\title{
Performance measurement and management in Portuguese law enforcement
}

\section{Patrícia Gomes and Silvia M. Mendes}

Performance measurement of police services is complicated by ambiguous and complex goal-and objectives-setting, and by the difficulties of measuring outputs. This article looks at the organizational and management changes being made in Portuguese police forces. The authors fill a gap in the literature on performance measurement in Portugal by taking a national approach to the study of how law enforcement agencies are introducing new management accounting changes. The article therefore widens the debate on performance measurement and performance improvements in law enforcement.

Keywords: Law enforcement; performance measurement; PIs; police, Portugal, PSP.

Many public sector organizations worldwide have undergone structural reforms in an attempt to increase efficiency, efficacy, and the quality of service. The new public management (NPM) agenda was the starting point (Hood, 1995; Lapsley, 1999, 2008), introducing a new culture of service delivery and performance evaluation, based on performance measurement. Performance indicators (PIs) were designed to help managers achieve efficiency and effectiveness and promote better decisions towards continuous improvement (Rautiainen et al., 2011).

Law enforcement is one public service area that has adopted this new performance culture (Carmona and Grönlund, 2003; Collier, 2006; Manning, 2008; Rautiainen et al., 2011). Several countries, such as Australia, Canada, Finland, the Netherlands, New Zealand, Portugal, Spain, Sweden, the UK and the USA, have implemented performance measurement in law enforcement (Loveday, 1995; Collier, 2001a, 2001 b, 2004; Carmona and Grönlund, 2003; Hoque et al., 2004; Hoogenboezem and Hoogenboezem, 2005; Gomes et al., 2008; Rautiainen et al., 2011). The use of the balanced scorecard (BSC) in the Swedish (Carmona and Grönlund, 2003) and Scottish (Wisniewski and Dickson, 2001) police systems are also important examples of innovative practices in police performance assessment.

Law enforcement in many countries is facing reductions in government funding together with increases in community demands for services. This had led to a move towards 'managing for outcomes' (Rautiainen et al., 2011). In this sense, police services have gradually come to incorporate performance measurement and management in their management models (Loveday, 1995; Rogerson, 1995; Collier, 2001b, 2004; Carmona and Grönlund, 2003; Hoque et al., 2004; Lambropoulou, 2004; Rautiainen et al., 2011). The aim is to measure outcomes of police work and their relationship with output measures, based on the capacity to carry out their operational activities with available resources and on the capacity to increase the level of public safety.

This is difficult to do in policing because of the ambiguity in the conceptualization of performance and because disclosure of information is often guarded (Carter et al., 1993; Carmona and Grönlund, 2003). In addition, different stakeholders have different views about what constitutes good performance (Carmona and Grönlund, 2003). Police activities are essentially intangible and not easily quantified: for example providing the public with a feeling of safety, building relationships with communities, and multi-agency policing. Therefore, caution needs to be exercised when developing a performance measurement system if the objective is to capture the quality and effectiveness of police work.
Patricia Gomes is a professor at the Polytechnic Institute of Cávado and Ave, Portugal.

Silvia M. Mendes is a professor at the University of Minho, Portugal. 


\section{Performance measurement in law} enforcement

Police activities are largely determined by external, or environmental, factors which are hard to control-socio-economic and demographic variables (Collier, 1998, 2001b; Drake and Simper, 2005). Moreover, a quantitative approach can be problematic because it 'cannot capture the dynamics of police/public interactions at the micro level, and fails to produce organizational or individual learning of any future worth' (Shilston, 2008, p. 359). In this sense, Carter et al. (1993, p. 7) assert that performance measures of police activities are, in fact, performance measures of the community as a whole. In order to adopt multidimensional performance measurement systems, law enforcement agencies need to define qualitative and quantitative performance measures (Jackson, 1993; Guthrie and English, 1997; Kloot and Martin, 2000) that relate results and operating activities.

Police forces carry out diverse functions, ranging from crime prevention, community policing, law enforcement and the maintenance of public order, prevention of drug use and trafficking, and promoting road safety and feelings of security. Consequently, there is a risk of ambiguity in goal-setting and in the measurability of outputs and outcomes. To deal with these complexities, performance measurement must have a clear definition of goals and responsibilities, as well as a clear picture of core activities (Rogerson, 1995; Verbeeten, 2008).

Policing has been changing from a focus on the reduction of crime to more of an emphasis on community policing-where citizens play an important role in raising the quality of urban life (Carmona and Grönlund, 2003 , p. 1481). Crime rate is not sufficient to evaluate police performance; more qualitative and quantitative information on outputs and outcomes need to be included. Therefore, a multidimensional approach is needed to attempt to draw a clear picture of police performance (Carmona and Salvador, 2003; Rautiainen et al., 2011).

The UK was a pioneer in adopting PIs in law enforcement in the 1980s. Performance measurement of public service delivery has come a long way since then, particularly in financial management (Rogerson, 1995). In the UK in the mid $1990 \mathrm{~s}$, greater freedoms were given to chief constables to manage their resources and be held more accountable and police forces were required to use 'performance targets that would prioritize activity of the following year' (Collier, 2001b, p. 473). The linkage between funding and performance and the promotion of the strategic planning were the most important aspects of these reforms (Rogerson, 1995). This reform agenda led to the Police Reform Act 2002 which considers how police forces can show value for money based on government strategic policy targets.

More recently in the $\mathrm{UK}$, in the mid 2000 s, a major new initiative was adopted to foster community policing-the neighbourhood policing programme (Neyroud, 2008). This programme aims to reduce the gap between police performance and public confidence, drawing on evidence from the UK, the USA, and Australia. Unlike earlier models, the focus is on signalling 'crimes that have a disproportionate impact on local public perceptions of policing and on measures of trust and confidence that local communities have in the police' (Innes, 2004, cited by Neyroud, 2008, p. 343).

Other countries have followed the British example. Portugal is one such case. The Portuguese changes include the introduction of a new paradigm based on community policing and the measurement of performance (Gomes et al., 2008). In Portugal, there are two national police forces responsible for the prevention and detection of crime and the maintenance of law and order:

- The Guarda Nacional Republicana (GNR), which polices smaller rural population centres and rural areas.

- The Polícia de Segurança Pública (PSP), which polices urban centres (Barros, 2006).

Both report to the Ministry of Internal Administration, and have very limited administrative and financial autonomy. There is a national structure and a rigid management and accountability structure. In addition, Portugal has two other police forces:

- Polícia Judiciária (PJ): responsible for criminal investigation and accountable to the Ministry of Justice.

- The Polícia Municipal (PM), which oversees specific urban civil activities and is accountable both to the Ministry of the Territorial Planning and the Ministry of Internal Administration. 
The Portuguese government is reforming the police system to create a unitary model, like the one in Spain. This will encompass the GNR, the PSP, and the PJ. However, Portugal is a relative late comer to NPM (Carvalho et al., 2006) and so financial and management initiatives are not as advanced as in the UK (Araújo, 2001; Carvalho et al., 2006). However, reforms have been introduced in at least one of the four national Portuguese police forces-the PSP. This article focuses on those changes.

\section{Performance measurement and management in the PSP}

The PSP's mission is to assure legal democracy, internal safety, and human rights. Five strategic goals have been defined for the PSP (PSP Report, 2008): increase citizen safety; reduce criminality and insecurity; promote road safety; improve quality of service; increase skills in human resources.

The PSP has a hierarchical structure led by a national director appointed by the Ministry of Internal Administration and is organized into two regional constabularies, two metropolitan constabularies, and 16 district constabularies. The total budget of the PSP was about 612 million euro in 2008, the majority of which (about 93\%) was allocated to staffing. The PSP had over 20,000 staff in 2007 and 2008 (see table 1). This number decreased from 2007 to 2008 , following government pressure to reduce the number of civil servants. Police officers constitute about $80 \%$ of total staff, so the ratio of police officers per 1000 inhabitants is about 1.6 police officers (Portugal's population is almost 11 million).

However, the results of a nationwide survey that we conducted in 2006, showed that PSP police officers spend only $40 \%$ of their time on community policing. The rest of their time is spent on administrative and secondary functions. This is a problem in terms of effective performance measurement because people tend to evaluate police services in terms of the number of police officers they see patrolling the streets (Collier, $2001 \mathrm{~b})$.

In recent years, the PSP has been under pressure to introduce a management model that is more pro-active and more citizenoriented. As in other parts of the Portuguese public sector, the police have introduced management by objectives (Gomes et al., 2008). Our 2006 survey applied to all PSP agency heads and focused on the development of performance measurement systems.* Respondents thought that the most useful performance measures were around citizen satisfaction, employees' performance and operational efficiency. Police chiefs paid little attention to financial measures. This focus on citizens, employees, and quality is in line with the PSP's mission.

About $75 \%$ of respondents said that PSP's mission and associated goals were defined clearly. In addition, around $66 \%$ considered that measurable targets were accurately defined and that results/achievements were being measured. These results indicate that performance measurement systems are being considered or are already in use in PSP agencies.

Regarding the main constraints in the implementation of performance measurement systems, respondents highlighted the short-term approach taken by public policy-makers (the lack of a strategic and pro-active management model), the lack of financial autonomy, the disconnection between the performance measurement system and the reward system, and resistance to change.

More recently, there have been two major organizational changes to the PSP management model:

- The introduction of an integrated program of community policing (PIPP) which aims to articulate crime prevention and proximity policing with public order, criminal investigation, and police information.

- New legislation introducing changes in the performance measurement and assessment of public services aimed at promoting accountability and improving decision-making.

*A nationwide postal survey was sent in early 2006 to all Portuguese police chiefs except in the GNR. A total of 243 questionnaires was returned (response rate $=48 \%$ ). The questionnaire explored the extent of BSC application and management's willingness to apply the BSC. The questionnaire was informed by face-to-face interviews conducted with police chiefs. The questionnaire had four sections: descriptions of the responding officers and agencies; the perceived importance of specific NPM issues and on the level of effective autonomy; the use and importance of performance measures; and level of knowledge of and predisposition toward the BSC. 


\section{PIPP}

PIPP is a government programme which uses strategic initiatives and operational objectives to reform police services with improved co-ordination, evaluation, and training. The goal is to articulate core police activities (crime prevention, community policing, public order, and crime investigation) in order to increase efficiency in resource allocation and improve the quality of service delivery. PIPP's goals are similar to those in the UK's neighbourhood policing programme. PIPP was initially implemented as a pilot project in 26 subunits of the PSP in the year 2006 and by the end of 2008, its coverage expanded to 112 subunits.

Two specialized teams were introduced in each subunit: a 'proximity and victim support team' (responsible for security and policing in each area of responsibility) and a 'safe school programme team' (responsible for security and surveillance in schools). The officers in these teams work closely with residents, and particularly with vulnerable people (for example young children, teenagers, elderly, residents of problem neighbourhoods). Another innovative procedure under the PIPP is the evaluation of police performance (financed by the Programa Operacional da Administração Pública-POPA). Police performance is assessed both from the perspective of the population (perceptions of police work carried out, feelings of security or insecurity, and PIPP's impact on society); and from the perspective of the police officers (how they think they relate to the population and the structure in which they operate).

PIPP was first evaluated in October 2006 and then again in December 2007. The results of these evaluations showed that people perceived an increase in the number of police officers on the streets between 2006 and 2007 (PSP Report, 2008). Although the population saw this change as positive, no structural changes were detected. Police officers also valued proximity to, and good relationships with, the general population, as well as with other police forces and organizations and other community services. Despite generally positive results, police officers said that police work was still focused on the patrol car and continued to be very much a reactive police force (PSP Report, 2008, pp. 207-211).

\section{A new performance measurement and assessment system in the PSP}

Other changes also occurred in the performance assessment of police work in Portugal. For example an integrated system for management and performance assessment of public administration (SIADAP) was introduced in 2007. This is a management by objectives model which aims to strengthen a culture of assessment and accountability in the public sector and to monitor whether the service is complying with its organizational mission. Thus, this is a new model of management and performance assessment that focuses on the alignment between service performance and the performance of those working in itboth management (top and middle) and employees. 'The success of SIADAP and management by objectives shall be largely based on the existence of quality management information systems that supply timely, relevant, and accurate data on the evolution of results' (Ministry of Finance, 2007, p. 19). In addition to the SIADAP, a new performance management tool was also introduced to help the process of performance assessment of each servicethe framework of assessment and accountability (QUAR).

SIADAP and QUAR have been compulsory for law enforcement since 2007 and PSP performance based on these new requirements was first assessed in 2008. According these requirements, the first QUAR of the PSP was elaborated for the year 2008 and included multi-annual strategic objectives (goals), annual objectives

Table 1. PSP staffing.

\begin{tabular}{lrrr}
\hline Staff & 2007 & 2008 & Variation \\
\hline Senior officials & 662 & 811 & 149 \\
Chiefs and deputy chiefs & 2648 & 2530 & -118 \\
Police officers & 18,973 & 17,976 & -997 \\
Employees (non-police functions) & 1016 & 826 & -190 \\
\hline Total & 23,299 & 22143 & -1156 \\
\hline
\end{tabular}

Sources: PSP Social Balance (2007 and 2008) and PSP Activities Report (2008)—see www.psp.pt 
(operational objectives), key performance indicators (KPIs), as well as the respective verification sources. Another important aspect is that performance measures are organized into:

-Effectiveness-measures the extent to which a service achieves its objectives and obtains or exceeds the expected results.

-Efficiency-measures the relationship between outputs and the resources used.

-Quality-measures the extent to which outputs meet users' needs.

The performance measurement system must be designed to work with the planning and control system and with the management cycle, therefore providing a tool for monitoring and assessing compliance with strategic goals and annual targets based on quantitative indicators. Five key stages are involved:

- Setting objectives for each organizational unit for the following year.

- Approval of the budget and statement of its personnel.

- Definition of the activities for the coming year and the key PIs (both for units and for the organization as a whole).

- Monitoring the revision of the objectives.

- Performance report with qualitative and quantitative information on the achievements and annual self-assessment.

The monitoring and revision of the objectives allows for feedback on what has already been accomplished and the introduction of improvements throughout the system. The performance report explains the achieved levels of effectiveness, efficiency, and quality compared with the commitments set out in the planning and control documents. Political leaders therefore have quantitative and qualitative information on outputs and outcomes in order to evaluate the performance of top managers.

As a result of these organizational changes, policing in Portugal has moved from a reactive and rigid model to a more pro-active and modern management model.

\section{Framework of performance indicators used by the PSP}

Following SIADAP requirements, the PSP elaborates a QUAR for each fiscal year that includes a framework of PIs based on measures of effectiveness, efficiency, and quality. Operational objectives (based on the five key stages) are defined with objective and quantitative PIs. Defining targets allows an organization to assess its achievements, as well as quantify gaps between desired and achieved goals. The 2008 PSP QUAR consisted of 13 objectives, seven effectiveness indicators, four efficiency indicators, and two quality indicators. Thus, a single indicator and target was used to measure achievements according to each operational objective. Table 2 summarizes the main PIs adopted by the PSP for self-assessment for this year.

Some interesting and important issues emerge from the analysis of table 2. First, different metrics are used by the PSP to measure PIs (for example number of actions, days). Also, there is a high level of consistency between objectives, indicators, and targets.

Second, effectiveness measures are greatly oriented toward the PIPP objectives (i.e. the percentage of subunits that integrate the PIPP and the percentage of visible policing actions), particularly the reduction of crime (the number of special operations in crime prevention). The PSP emphasizes community policing actions and police presence in the streets to increase the public's feeling of security. However, the PSP did not develop any measures aimed at increasing public safety or reducing crime rates, which are important outputs of police work.

Third, the efficiency measures are oriented towards processes. There is an emphasis on time response and the simplification of processes, such as the reduction of the average time taken to issue licences. This could be a consequence of new administrative procedures introduced in the Portuguese public sector called SIMPLEX, which aims to shorten and simplify administrative procedures-reducing 'red tape'. There is still a lot of room for improvement, particularly in the short term with additional measures of outputs, outcomes, and the use of resources.

Finally, quality measures are focused on service delivery and have a greater orientation toward the implementation of good practices in the PSP. With regard to achievements, the majority of the objectives have been met, and, in most cases, the PSP exceeded the targets in 2008 and again in 2009 for effectiveness measures. Although other factors can be associated with improvements in the PSP, the results shown for 2008 (and 2009) show some degree of 
success of the goal- and results-oriented management reforms.

Our survey results were consistent with the framework. Survey respondents agreed that the level of productivity, employee and citizen satisfaction, response time, the reduction of the crime rate, and the number of complaints are some of the most important PIs for measuring performance in police agencies.

\section{Concluding remarks}

Measuring performance in law enforcement is challenging due to factors that cannot be controlled (community behaviour, unemployment etc.), as well as the lack of a 'performance culture' (Carter et al., 1993; Collier, 2006). Unintended consequences can also result when systems are introduced (de Bruijn, 2002; Thomas, 2006).

Despite all of the limitations, many governments have implemented police performance measurement systems. Crime rate is no longer the only bottom-line measure of performance in policing. Increasing demands and limited resources require that law enforcement managers improve their capacity to serve their communities by preventing and controlling crime. In Portugal, the implementation of a new performance measurement and assessment model in the PSP is still novel. The emphasis has been placed on increasing community policing (based on the PIPP objectives), making police officers more visible on the streets, and simplifying procedures.

However, the Portuguese police need to pay more attention to the measurement of outputs, outcomes, and the use of resources. For example, PIs need to be developed to measure the sense of public security and safety, the level of the fear of crime, the percentage of calls answered within target response times, the number of public complaints per 1000 officers and the percentage of complaints substantiated can

Table 2. Performance indicators and achievements of the PSP.

\begin{tabular}{|c|c|c|c|c|c|}
\hline Measures & Objectives & Indicators & $\begin{array}{l}\text { Targets } \\
(2008)\end{array}$ & $\begin{array}{l}2008 \text { achievements } \\
\text { (results relative } \\
\text { to } 2008 \text { targets) }\end{array}$ & $\begin{array}{l}2009 \text { achievements } \\
\text { (results relative } \\
\text { to } 2008 \text { targets) }\end{array}$ \\
\hline \multirow[t]{4}{*}{ Effectiveness } & $\begin{array}{l}\text { O1: Increase number of } \\
\text { subunits that integrate } \\
\text { the PIPP by } 60 \%\end{array}$ & $\begin{array}{l}\text { No. of subunits that } \\
\text { integrate the PIPP/ } \\
\text { Total No. of subunits }\end{array}$ & 128 subunits & $\begin{array}{l}112 \text { subunits } \\
(-12.5 \%)\end{array}$ & $\begin{array}{l}150 \text { subunits } \\
(+17.2 \%)\end{array}$ \\
\hline & $\begin{array}{l}\text { O2: Increase the number of } \\
\text { visible police actions/ } \\
\text { activities by } 7.5 \%\end{array}$ & $\begin{array}{l}\text { No. of visible police } \\
\text { actions in } 2008 / \\
\text { No. of visible police } \\
\text { actions in } 2007 * 100\end{array}$ & 1602 actions & $\begin{array}{l}2888 \text { actions } \\
(+180.27 \%)\end{array}$ & $\begin{array}{l}\text { 10,598 operations } \\
(+561.5 \%)\end{array}$ \\
\hline & $\begin{array}{l}\text { O3: Increase to } 40 \text { the number } \\
\text { of special operations on crime } \\
\text { prevention }\end{array}$ & $\begin{array}{l}\text { No. of special } \\
\text { operations on } \\
\text { crime prevention }\end{array}$ & 40 operations & $\begin{array}{l}603 \text { operations } \\
(+1507.5 \%)\end{array}$ & $\begin{array}{l}703 \text { operations } \\
(+1.657 \%)\end{array}$ \\
\hline & $\begin{array}{l}\text { O4: Increase in } 5 \% \text { the number } \\
\text { of enforcement actions oriented } \\
\text { to risk factors on road }\end{array}$ & $\begin{array}{l}\text { (Total actions in 2008/ } \\
\text { Total actions in 2007) } \\
* 100\end{array}$ & 13,823 actions & $\begin{array}{l}14,789 \text { actions } \\
(+6,99 \%)\end{array}$ & $\begin{array}{l}\text { 17,314 operations } \\
(+25.25 \%)\end{array}$ \\
\hline \multirow[t]{2}{*}{ Efficiency } & $\begin{array}{l}\text { O1: Reduction of } 10 \% \text { in } \\
\text { average time (days) to issue } \\
\text { licences for private security }\end{array}$ & $\begin{array}{l}\text { (Average time [days] } \\
\text { in 2007/Average time } \\
\text { [days] in 2008)*100 }\end{array}$ & 288 days & 90 days $(+220 \%)$ & $\mathrm{N} / \mathrm{a}$ \\
\hline & $\begin{array}{l}\text { O2: Reduction of } 10 \% \text { in } \\
\text { average time (days) to issue } \\
\text { weapons licences }\end{array}$ & $\begin{array}{l}\text { (Average time [days] in } \\
\text { 2007/Average time } \\
\text { [days] in 2008)*100 }\end{array}$ & 67 days & 66 days $(+1.52 \%)$ & $\mathrm{N} / \mathrm{a}$ \\
\hline \multirow[t]{2}{*}{ Quality } & $\begin{array}{l}\text { O1: Disseminate } 3 \text { good } \\
\text { practices on community } \\
\text { policing }\end{array}$ & $\begin{array}{l}\text { No. of good practices } \\
\text { reported via the PSP } \\
\text { intranet }\end{array}$ & 3 good practices & $\begin{array}{l}6 \text { good practices } \\
(+100 \%)\end{array}$ & $\mathrm{N} / \mathrm{a}$ \\
\hline & $\begin{array}{l}\text { O2: Dematerialize } 20 \% \text { of } \\
\text { processes of weapon licensing } \\
\text { processes registered in } 2008\end{array}$ & $\begin{array}{l}\text { (No. of dematerialized } \\
\text { processes in 2008/Total } \\
\text { processes registered in } \\
2008) * 100\end{array}$ & $20 \%$ & $20.6 \%(+3 \%)$ & $\mathrm{N} / \mathrm{a}$ \\
\hline
\end{tabular}


lead to substantial improvements in the performance assessment of police work. In addition measures are needed to produce a better picture of the police performance.

In summary, the Portuguese police service has been focusing on performance measurement and assessment for the past 10 years as a consequence of important changes in the country's police management paradigm. Similarly with many other countries, the definition of efficiency, effectiveness, and quality measures, with associated targets, have become important aspects of the police management model in Portugal. In the short term, these changes have produced significant improvements in police performance.

\section{References}

Araújo, J. (2001), Improving public service delivery: the crossroads between NPM and traditional bureaucracy. Public Administration, 79, 4, pp. 915-932.

de Bruijn, H. (2002), Managing Performance in the Public Sector (Routledge, London).

Barros, C. (2006), Productivity growth in the Lisbon police force. Public Organization Review, 6, pp. 21-35.

Carmona, S. and Grönlund, A. (2003), Measures vs actions: the balanced scorecard in Swedish law enforcement. International Journal of Operations \& Production Management, 23, 12, pp. 1475-1496.

Carter, N., Klein, R. and Day, P. (1993), How Organizations Measure Success: The Use of Performance Indicators in Government (Routledge, London).

Carvalho, J., Fernandes, M. J., Lambert, V. and Lapsley, I. (2006), Measuring fire service performance: a comparative study. International Journal of Public Sector Management, 19, 2, pp. 165-179.

Collier, P. (1998), Operations and accountability: the role of performance indicators, financial devolution and strategy in the management of a police force. International Journal of Police Science and Management, 1, 1, pp. 81-93.

Collier, P. (2001a), Police performance management-an ethical dilemma. In Neyroud, P. and Alan, B. (Eds), Policing, Ethics and Human Rights (Willan Publishing/ Routledge, London).

Collier, P. (2001b), The power of accounting: a field study of local financial management in a police force. Management Accounting Research, 12, pp. 465-486.

Collier, P. (2004), Police in South Africa: replication and resistance to new public management reforms. Public Management Review, 6, 1, pp. 1-20.

Collier, P. (2006), Costing police services: the politicization of accounting. Critical Perspectives on Accounting, 17, pp. 57-86.

Drake, L. and Simper, R. (2005), The measurement of police force efficiency: an assessment of UK. Contemporary Economic Policy, 23, 4, pp. 465-482.

Gomes, P., Mendes, S. and Carvalho, J. (2008), Use of performance measurement in the public sector: the case of the police service. In Jorge, S. (Ed), Implementing Reforms in Public Sector Accounting (Coimbra University Press, Portugal).

Guthrie, J. and English, L. (1997), Performance information and program evaluation in the Australian public sector. International Journal of Public Sector Management, 10, 3, pp. 154164.

Hoque, Z., Arends, S. and Alexander, R. (2004), Policing the police service: a case study of the rise of 'new public management' within an Australian police service. Accounting, Auditing E Accountability Journal, 17, 1, pp. 59-84.

Hood, C. (1995), The 'new public management' in the 1980s: variations on a theme. Accounting, Organizations E Society, 20, 2/3, pp. 93-109.

Hoogenboezem, A. and Hoogenboezem, B. (2005), Coping with targets: performance measurement in the Netherlands police. International Journal of Productivity and Performance Management, 54, 7, pp. 568-578. Jackson, P. (1993), Public service performance evaluation: a strategic perspective. Public Money E Management, 13, 4, pp. 9-14.

Kloot, L. and Martin, J. (2000), Strategic performance management: a balanced approach to performance management issues in local government. Management Accounting Research, 11, pp. 231-251.

Lambropoulou, E. (2004). Citizen's safety, business trust and Greek police. International Review of Administrative Sciences, 70, 1, pp. 89-110.

Lapsley, I. (1999), Accounting and the new public management: instruments of substantive efficiency or a rationalizing modernity? Financial Accountability and Management, 15, 3/4, pp. 201-207.

Lapsley, I. (2008), The NPM agenda: back to the future. Financial Accountability and Management, 24, 1, pp. 77-96.

Loveday, B. (1995), Reforming the police: from local service to state police? Political Quarterly, pp. 141-156.

Manning, P. (2008), Performance rituals. 
Policing: A Journal of Policy and Practice, 2, 3, pp. 284-293.

Ministry of Finance, (2007), State Budget for 2008 Report. See http://www.gpeari.minfinancas.pt/arquivo-interno-de-ficheiros/ o r c a m e n t o - d o - e s t a d o/ Relatorio\%200E2008_EN.pdf/view

Neyroud, P. (2008), Past, present and future performance: lessons and prospects for the measurement of police performance. Policing, 2, 3, pp. 340-348.

Rautiainen, A., Urquia, E. and Munoz, C. (2011), Analyzing and developing police performance indicators: a comparative case study of Spain and Finland. Paper presented at the European Accounting Association conference, Rome.

Rogerson, P. (1995), Performance measurement and policing: police service or law enforcement agency? Public \& Money
Management, 15, 4, pp. 25-30.

Shilston, T. (2008), One, two, three, what are we still counting for? Police performance regimes, public perceptions of service delivery and the failure of quantitative measurement. Policing, 2, 3, pp. 359-366.

Thomas, P. (2006), Performance Measurement, Reporting, Obstacles and Accountability (Australian National University Press, Canberra).

Verbeeten, M. (2008), Performance management practices in public sector organizations: impact on performance. Accounting, Auditing and Accountability Journal, 21, pp. 427-454.

Wisniewski, M. and Dickson, A. (2001), Measuring performance in Dumfries and Galloway constabulary with the balanced scorecard. Journal of the Operational Research Society, 52, pp. 1057-1066. 